\title{
Toric phakic implantable collamer lens for correction of astigmatism: I-year outcomes
}

This article was published in the following Dove Press journal:

Clinical Ophthalmology

I5 March 20II

Number of times this article has been viewed

\section{Erik L Mertens \\ Medipolis Eye Centre, Antwerp, Belgium}

Correspondence: Erik L Mertens Medipolis Eye Centre, Boomsesteenweg 223, 26I0 Wilrijk, Antwerp, Belgium

Tel +32 38282949

Fax +32 38208891

Email e.mertens@medipolis.be
Purpose: The purpose of this study was to assess predictability, efficacy, safety and stability in patients who received a toric implantable collamer lens to correct moderate to high myopic astigmatism.

Methods: Forty-three eyes of 23 patients underwent implantation of a toric implantable collamer lens (STAAR Surgical Inc) for astigmatism correction. Mean spherical refraction was $-4.98 \pm 3.49$ diopters (D) (range: 0 to $-13 \mathrm{D}$ ), and mean cylinder was $-2.62 \pm 0.97 \mathrm{D}$ (range: -1.00 to $-5.00 \mathrm{D}$ ). Main outcomes measures evaluated during a 12-month follow-up included uncorrected visual acuity (UCVA), refraction, best-corrected visual acuity (BCVA), vault, and adverse events.

Results: At 12 months the mean Snellen decimal UCVA was $0.87 \pm 0.27$ and mean BCVA was $0.94 \pm 0.21$, with an efficacy index of 1.05 . More than $60 \%$ of the eyes gained $\geq 1$ line of BCVA (17 eyes, safety index of 1.14). The treatment was highly predictable for spherical equivalent $\left(r^{2}=0.99\right)$ and astigmatic components: $\mathrm{J}_{0}\left(r^{2}=0.99\right)$ and $\mathrm{J}_{45}\left(r^{2}=0.90\right)$. The mean spherical equivalent dropped from $-7.29 \pm 3.4 \mathrm{D}$ to $-0.17 \pm 0.40 \mathrm{D}$ at 12 months. Of the attempted spherical equivalent, $76.7 \%$ of the eyes were within $\pm 0.50 \mathrm{D}$ and $97.7 \%$ eyes were within $\pm 1.00 \mathrm{D}$, respectively. For $\mathrm{J}_{0}$ and $\mathrm{J}_{45}, 97.7 \%$ and $83.7 \%$ were within $\pm 0.50 \mathrm{D}$, respectively.

Conclusion: The results of the present study support the safety, efficacy, and predictability of toric implantable collamer lens implantation to treat moderate to high myopic astigmatism.

Keywords: phakic intraocular lens, toric implantable collamer lens, astigmatism

\section{Introduction}

Clinical results of posterior phakic intraocular lenses (pIOLs) have confirmed this procedure as a promising treatment option for patients who cannot undergo keratorefractive procedures. ${ }^{1}$ The main advantages are the correction of higher levels of myopia, hyperopia, and astigmatism and the reversibility of the procedure..$^{2-12}$ Presently, one of the most successful pIOL, known as implantable collamer lens (ICL), is the Visian ICLV4 manufactured by STAAR Surgical (Monrovia, CA; Figure 1). The Visian ICL is the only posterior pIOL currently under revision for approval by the United States Food and Drug Administration (FDA) for the treatment of astigmatism. ${ }^{10}$

Several studies have been published on an anterior chamber iris-fixated toric pIOL $^{13-17}$ demonstrating a significant reduction in spherical and astigmatic refractive errors. However concerns still exist regarding potentially induced progressive endothelial cell loss. ${ }^{18}$ The recently published outcomes of the toric ICL ${ }^{8-12}$ showed good efficacy and predictability. Additionally, in cases in which keratorefractive or other alternative 


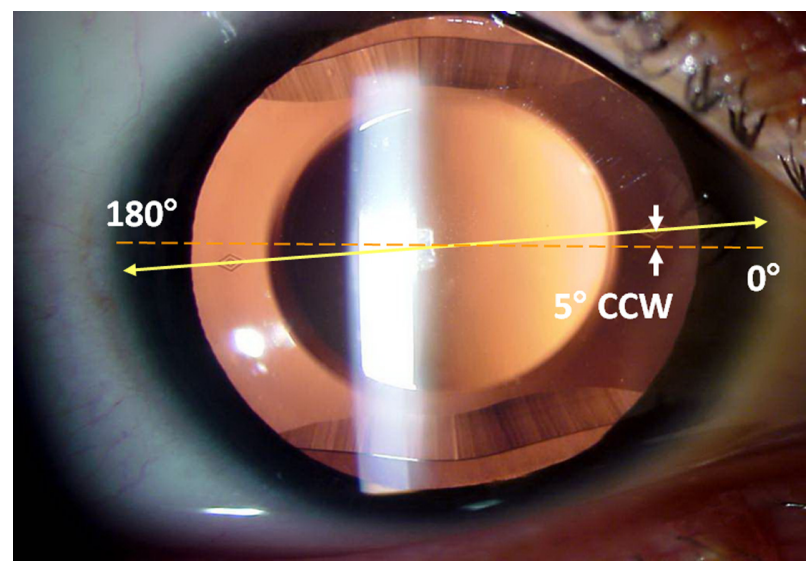

Figure I Toric Visian ICLV4 lens. Red dotted line indicates the eye's horizontal axis. Yellow line indicates lens horizontal axis connecting the two diamond-shaped marks of the toric ICL. The arrows indicate that the surgeon aligned the lens at $5^{\circ}$ counterclockwise from the horizontal meridian.

refractive procedures were not a good or feasible option, toric ICL implantation showed promising results. ${ }^{19-22}$

The purpose of this study was to assess safety, efficacy, predictability, and stability in patients who undergo toric ICL implantation to correct moderate to high myopic astigmatism with follow-up visits up to 12 months.

\section{Patients}

We prospectively studied 43 eyes of 23 patients, 17 (73.9\%) females and $6(26.1 \%)$ males, who underwent implantation of a toric ICL to correct myopic astigmatism at the Medipolis Eye Centre (Antwerp, Belgium). Mean patient age was $34.41 \pm 9.42$ years (range: 22 to 49 years). Table 1 shows the demographic data prior to surgery and parameters of implanted lenses.

The inclusion criteria were best-corrected distance visual acuity (BCVA) of 20/40 or better, stable refraction and clear

Table I Descriptive statistics for demographic data of patients and characteristics of implanted toric implantable collamer lens

\begin{tabular}{llll}
\hline & Mean & SD & $\begin{array}{l}\text { Range } \\
{[\text { min, max] }}\end{array}$ \\
\hline Age (years) & 34.41 & 9.42 & {$[22,49]$} \\
Refractive sphere (D) & -5.98 & 3.49 & {$[-13.5,0]$} \\
Refractive cylinder (D) & -2.62 & 0.97 & {$[-5,-1]$} \\
Flat keratometry & 43.10 & 1.72 & {$[39.63,47.13]$} \\
Steep keratometry & 45.38 & 1.84 & {$[40.75,49.00]$} \\
ICL size (mm) & 12.09 & 0.42 & {$[11.5,12.5]$} \\
ICL sphere (D) & -13.13 & 4.09 & {$[-21,-4.50]$} \\
ICL cylinder (D) & 3.24 & 1.32 & {$[0.5,6.0]$} \\
White-white (mm) & 11.66 & 0.35 & {$[10.8,12.5]$} \\
ACD (mm) & 3.19 & 0.32 & {$[2.80,3.82]$} \\
Corneal thickness $(\mu \mathrm{m})$ & 514.5 & 50.2 & {$[420,625]$} \\
\hline
\end{tabular}

Abbreviations: ICL, implantable collamer lens; ACD, anterior chamber depth from endothelium; SD, standard deviation. central cornea. The exclusion criteria included age $<22$ years, anterior chamber depth $<2.8 \mathrm{~mm}$ from endothelium, endothelial cell density $<2000 \mathrm{cell} / \mathrm{mm}^{2}$, cataract, history of glaucoma or retinal detachment, macular degeneration or retinopathy, neuro-ophthalmic diseases, and history of ocular inflammation. Before the TICL implantation, patients had a complete ophthalmologic examination, including refraction, keratometry, corneal topography, endothelial cell count, pachymetry, slit-lamp microscopy, Goldmann applanation tonometry, and binocular indirect ophthalmoscopy. The targeted refraction was emmetropia in all cases.

Toric ICL is a pIOL manufactured with an haptic design identical to the spherical $\mathrm{ICL}^{2}$ in terms of size, thickness, and shape, with central convex/concave optical zone, and cylinder as necessary to address each patient's astigmatic condition. ${ }^{8}$ Toric ICL power calculation was performed using the software provided by the manufacturer. Toric ICL is manufactured to minimize rotation and required the surgeon to rotate the toric ICL no more than $22.5^{\circ}$ from the horizontal meridian. Each toric ICL comes with a guide demonstrating the amount and direction of rotation from the horizontal axis required of the toric ICL to exactly align the toric ICL cylinder axis to the patients' required cylinder correction. All surgeries in this study were performed by one experienced surgeon (ELM) using topical and intracameral anesthesia. On the day of surgery, $0.5 \%$ tropicamide and $5 \%$ phenylephrine $\mathrm{HCl}$ were serially instilled for pupil dilation. Fifteen minutes before surgery a drop of preservative-free oxybuprocaine $\mathrm{HCl} 0.4 \%$ was instilled, followed by two to four drops of povidone iodine $5 \%$. The left eye underwent surgery first. Povidone iodine 10\% (Isobetadine; Viatris, Bad Homburg, Germany) was applied to the eyelids, the patient was draped and a lid speculum inserted. Four drops of preservative-free oxybuprocaine $\mathrm{HCl} 0.4 \%$ were used to further anaesthetize each eye. Three minutes before the start of surgery povidone iodine 5\% was administered to the ocular surface. The lens was removed from the sealed glass container and loaded inside the cartridge under the surgical microscope. The inner side of the cartridge was lubricated with methylcellulose and balanced salt solution. The lens was loaded making sure that both longitudinal edges of the haptic were symmetrically tucked under the edge of the cartridge with the lens vaulted anteriorly. The coaxial forceps designed by Zaldivar for ICL loading (Asico, Westmont, IL) was used to pull the lens through the cartridge tunnel. Inspection of the lens inside the tunnel was done to exclude twisting of the lens which helped making the injection inside the anterior chamber symmetrical, smooth, and reproducible. A preinked surgical marker was used to mark the target axis 
for toric ICL implantation using the previous dots marked at the slit lamp as reference for $0^{\circ}-180^{\circ}$. This provided the surgeon with extended lines over the cornea and pupil to facilitate alignment. A 1.0-mm side-port was made at 10 o'clock in the left eye and at 5 o'clock in the right eye followed by injection of intracameral preservative-free lidocaine $1 \%$ followed by viscoelastic (methylcellulose) with caution to not over-fill the anterior chamber. A 3-step temporal clear corneal incision: first a $600-\mu \mathrm{m}$ groove is made; tilting the tip of the knife a little bit upward and then parallel to the iris plane and enter the anterior chamber. The size of the incision was $2.6 \mathrm{~mm}$; this size allows smooth injection and has been reported to have negligible effect on postoperative astigmatism.

Firmly grasping the eye with the forceps, the tip of the cartridge was placed at the edge of the incision and the lens was slowly injected. The surgeon paid attention to the distal footplate to unfold in the anterior chamber before the trailing footplate was injected out of the cartridge. This prevents the lens from unfolding upside down in the anterior chamber. Once the lens unfolded in the anterior chamber the marks on the distal and proximal footplates were checked for proper orientation. Using the side-port and with Vukich's or Batlle's manipulator, the distal haptics were tucked under the iris. All manipulations were as peripheral as possible with no instruments touching the optic or crossing the pupillary zone. The proximal footplates were then tucked under the iris through the main incision. Using the line marks on the cornea we checked for toric ICL alignment. If rotation was needed we gently used the manipulator over the peripheral haptic and aligned the lens. Verification of lens centration and alignment is then done. Flush of viscoelastic was done by injection of saline through the side-port and pushing down on the main incision. At the completion of the procedure we injected intracameral preservative-free antibiotics (vancomycin $1 \mathrm{mg} / \mathrm{mL}$ ), checked sealing of the incision and administered one drop of dorzolamide $20 \%$ and timolol $5 \%$. In the recovery room a tablet of acetazolamide $250 \mathrm{mg}$ was administered orally to reduce further the intraocular pressure. Two hours after surgery the vault and alignment of the toric ICL was checked at the slit-lamp and the intraocular pressure was measured.

The tenets of the Declaration of Helsinki were followed in this study. Informed consent stating the potential risks and benefits of the lens implantation was obtained from all patients prior to surgery.

Follow-up visits were done at week 1, and months 1, 3, 6, and 12 postoperatively. All eyes were examined at each postoperative visit. Uncorrected visual acuity (UCVA), BCVA, slit-lamp examination, refraction, central separation between the ICL and the crystalline lens (vault) with slit lamp examination, and tonometry were evaluated. Vault value was assessed by comparing the separation between the lens and the posterior surface of the TICL to the corneal thickness using an optical section during routine slit-lamp examination. Estimation was registered in 0.25 steps (ie, 0.25 corneal thickness [CT], 0.5 CT, 0.75 CT, 1 CT, 1.25 CT, etc). For averaging, visual acuities were converted to $\log$ MAR and then the means and standard deviations were back calculated to Snellen acuity. Assessment of toric ICL outcomes was based on a comparison of preoperative with postoperative values of BCVA and UCVA for efficacy and safety and the achieved versus expected refractive outcomes postoperatively for predictability. Efficacy index (ratio of postoperative UCVA over preoperative BCVA) and safety index (ratio of postoperative over preoperative BCVA) were also calculated. Spherocylindrical refractive results were converted into vector expressed by 3-dioptric powers: $\mathrm{M}, \mathrm{J}_{0}$, and $\mathrm{J}_{45}$; with $\mathrm{M}$ being equal to the spherical equivalent of the given refractive error, and $\mathrm{J}_{0}$ and $\mathrm{J}_{45}$ the two Jackson cross cylinders equivalent to the conventional cylinder. Manifest refractions in conventional script notation ( $\mathrm{S}$ [sphere], $\mathrm{C}$ [cylinder], $\alpha$ [axis]) were converted to power vector coordinates by the following formulas:

$$
\begin{aligned}
& \mathrm{M}=\mathrm{S}+\mathrm{C} / 2 ; \mathrm{J}_{0}=(-\mathrm{C} / 2)^{*} \cos (2 \alpha) \text { and } \\
& \mathrm{J}_{45}=(-\mathrm{C} / 2)^{*} \sin (2 \alpha)^{23} .
\end{aligned}
$$

Data analysis was performed using SPSS for Windows (version 16.01; SPSS Inc, Chicago, IL). Normality of data distribution was checked by Kolmogorov-Smirnov test. Comparison of means with nonparametric Wilcoxon signed rank test. Hotelling $T^{2}$ test of multivariate analysis was used to explore statistically significant differences for refractive values and visual acuity outcomes. Differences were considered to be statistically significant when the $P$ value was $<0.05$.

\section{Results}

No complications occurred during the surgical procedures. No eye needed explantation and only one eye needed repositioning due to off-axis alignment 10 months after implantation. Decentration of the toric ICL optic was not observed, and no case of pupillary block was detected. At 12 months postsurgery, the mean spherical error was $-0.06 \pm 0.34 \mathrm{D}$ (ranging from 1.00 to $-1.00 \mathrm{D})$ and the mean cylinder value was $-0.20 \pm 0.43 \mathrm{D}$ (ranging from 0 to $-1.50 \mathrm{D}$ ).

In relation to predictability, Figure 2 shows the distribution of manifest refractive cylinder before toric ICL implantation compared with the 12-month visit outcomes. At the 12-month follow-up visit, $43(100 \%)$ of eyes with the toric ICL 


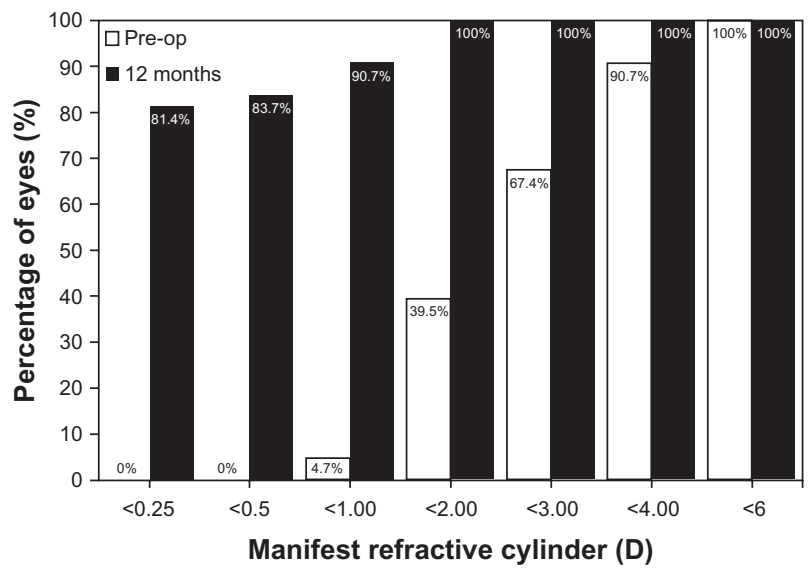

Figure 2 Preoperative (preop) versus I2-month postoperative refractive cylinder in diopters (d) after toric implantable collamer lens implantation.

had $\leq 2.0$ D of cylinder, compared with 17 (39.5\%) preoperatively, with $39(90.7 \%$ ) eyes having a refractive cylinder $\leq 1.0 \mathrm{D}$. Furthermore, no eyes $(0.0 \%)$ preoperatively had refractive cylinder of $0.50 \mathrm{D}$, whereas 36 eyes $(83.7 \%)$ had $\leq 0.5 \mathrm{D}$ and $35(81.4 \%)$ had $\leq 0.25 \mathrm{D}$ of refractive cylinder at 12 months. The deviation of the achieved from the expected $M$ refraction was calculated (see Figure 3). At 12 months, the mean M

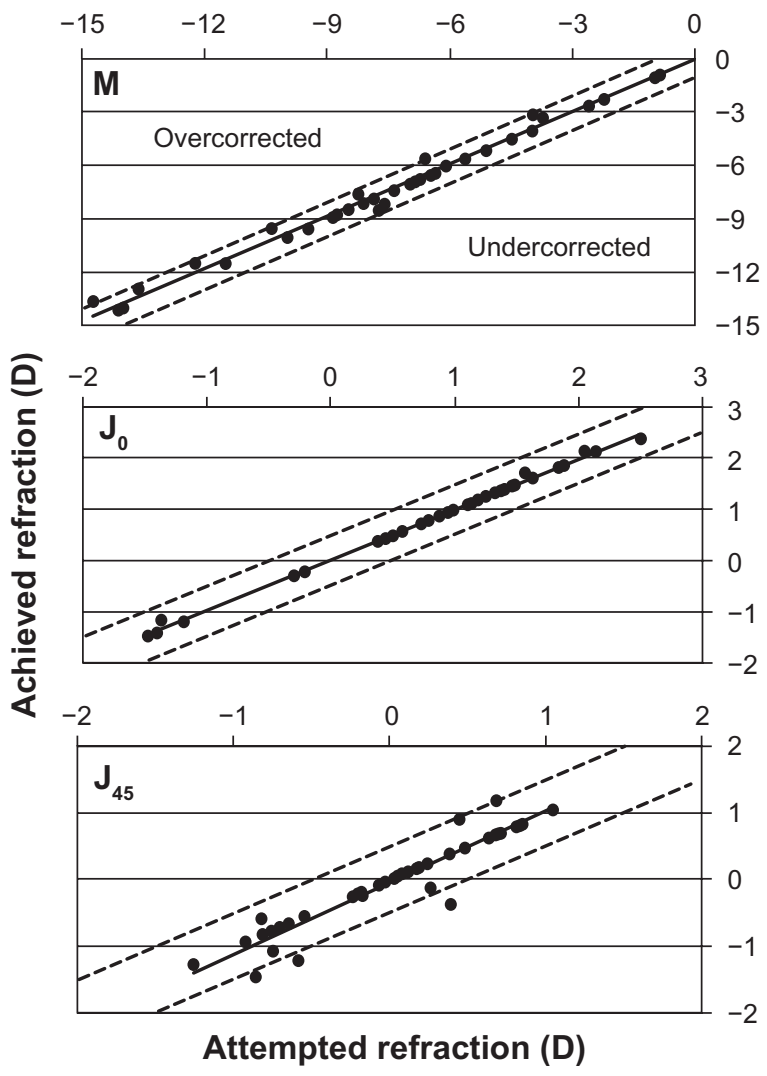

Figure 3 Plots of achieved against attempted correction (predictability) of spherical equivalent $(M)$ in diopters $(D)$ and the astigmatic components $\left(J_{0}\right.$ and $\left.J_{45}\right) 12$ months after toric implantable collamer lens implantation. Coefficients of determination $\left(r^{2}\right)$ are $0.99,0.99$, and 0.90 for $M, J_{0}$, and $\mathrm{J}_{45}$, respectively.

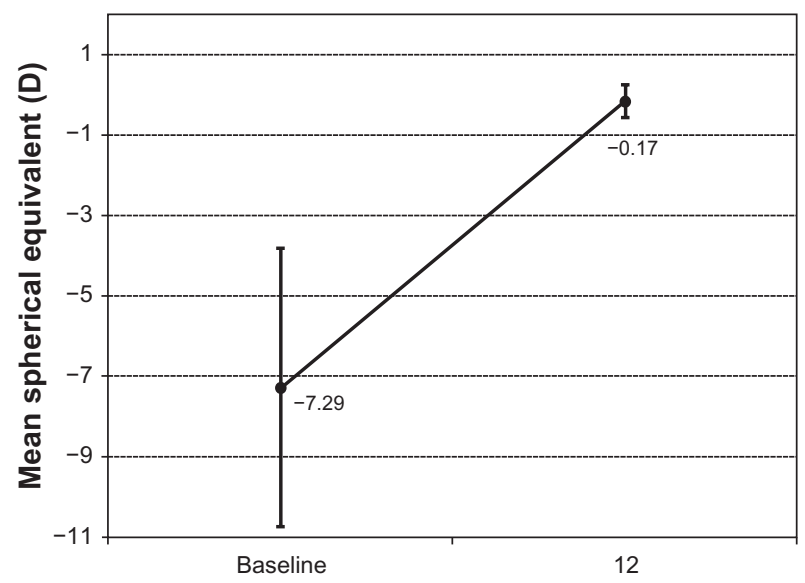

Follow-up period (months)

Figure 4 Time course of the spherical equivalent $(M)$ in diopters (stability) after toric implantable collamer lens implantation.

was $-0.17 \pm 0.40 \mathrm{D}$ with $33(76.7 \%)$ of the eyes within \pm 0.50 $\mathrm{D}$ and $42(97.7 \%)$ were within $\pm 1.00 \mathrm{D}$ of the desired $\mathrm{M}$ refraction $\left(r^{2}=0.99\right)$. For the astigmatic components, 42 eyes $(97.7 \%)$ and $36(83.7 \%)$ of eyes were within $\pm 0.50 \mathrm{D}$ for $\mathrm{J}_{0}$ $\left(r^{2}=0.99\right)$ and $\mathrm{J}_{45}\left(r^{2}=0.90\right)$, respectively.

The improvement in $\mathrm{M}$ refractive error is graphically illustrated in Figure 4. The mean $\mathrm{M}$ dropped significantly from $-7.29 \pm 3.4 \mathrm{D}$ to $-0.17 \pm 0.40 \mathrm{D}$ at 12 months $(P<0.05)$. Figure 5 shows the astigmatic components of the power vector as represented by the two-dimensional vector plot $\left(\mathrm{J}_{0}, \mathrm{~J}_{45}\right)$ where the tight distribution of points around zero is evident 12 months after surgery compared to preoperative data. The origin in this graph $(0,0)$ represents an eye free of astigmatism. A multivariate Hotelling $T^{2}$ test confirmed that the mean power vector after surgery was not significantly different from a vector of zero length $(P=0.3256)$.

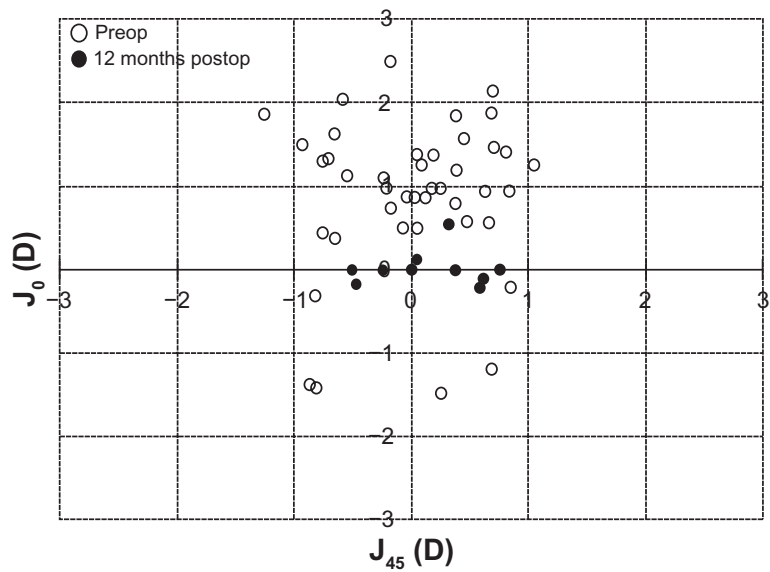

Figure 5 Scatter plot of the astigmatic vectors $\left(J_{0}\right.$ and $\left.J_{45}\right)$ before and 12 months after toric implantable collamer lens implantation. The more central location of postoperative data around 0 represents the reduction of preoperative astigmatism by the implantation of the toric implantable collamer lens. Note that $(0,0)$ represents an eye free of astigmatism. 


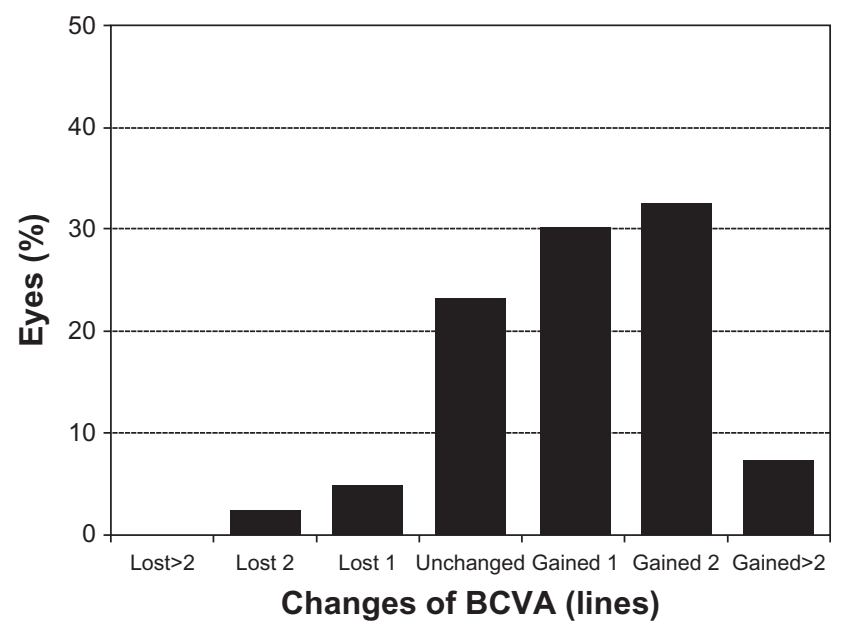

Figure 6 Changes in best-corrected distance visual acuity (BCVA) (safety) after 12 months of toric implantable collamer lens implantation.

Figure 6 shows the safety results for toric ICL implantation. Twelve months after surgery none of the examined eyes had lost $>2$ lines of BCVA; one eye lost 2 lines, two (4.7\%) eyes lost 1 line, 10 eyes (23.3\%) did not change after surgery, while 13 eyes (30.2\%) gained 1 line, 14 (32.6\%) eyes gained 2 lines, and three eyes gained $>2$ lines of BCVA. The safety index at 12 months was 1.14. Figure 7 represents the cumulative BCVA at baseline and 12 months after surgery. All eyes showed a
BCVA of 20/63 or better with more than $93.0 \%$ (40 eyes) of eyes with BCVA of 20/32 or better and also an increase in the amount of eyes with BCVA of $20 / 20$ or better, from $30.2 \%$ (13 eyes) at baseline to $69.8 \%$ (30 eyes) after 12 months.

In relation to the efficacy, Figure 8 shows the changes in UCVA and BCVA. Before surgery the mean Snellen decimal UCVA was $0.09 \pm 0.07$ (range: 0.05 to 0.2 ) while BCVA was $0.83 \pm 0.18$ (range: 0.5 to 1.2 ). At 12 months, the mean UCVA was $0.87 \pm 0.27$ (range 0.2 to 1.2 ) and the mean BCVA was $0.94 \pm 0.21$ (range 0.5 to 1.2 ). The overall efficacy was 1.05 . At the 12-month examination 25 (58.1\%) eyes had 20/20 or better UCVA, compared with 13 (30.2\%) BCVA at baseline. Furthermore, 31 (72\%) eyes had 12-month postoperative UCVA equal to or better than preoperative BCVA and 12 (28\%) eyes having 12-month postoperative UCVA lower than preoperative BCVA.

During the entire follow-up period we did not observe any chronic increased postoperative intraocular pressure (IOP). No pupillary block was detected. Anterior subcapsular cataract development was not observed over the entire follow-up period and mean IOP was $14.4 \pm 3.3 \mathrm{mmHg}$ (ranging from 8 to $20 \mathrm{mmHg}$ ). Mean vault was $0.94 \pm 0.20 \mathrm{CT}$ and changes during the follow-up period were very small without statistical significance during the follow-up period $(P>0.05)$.

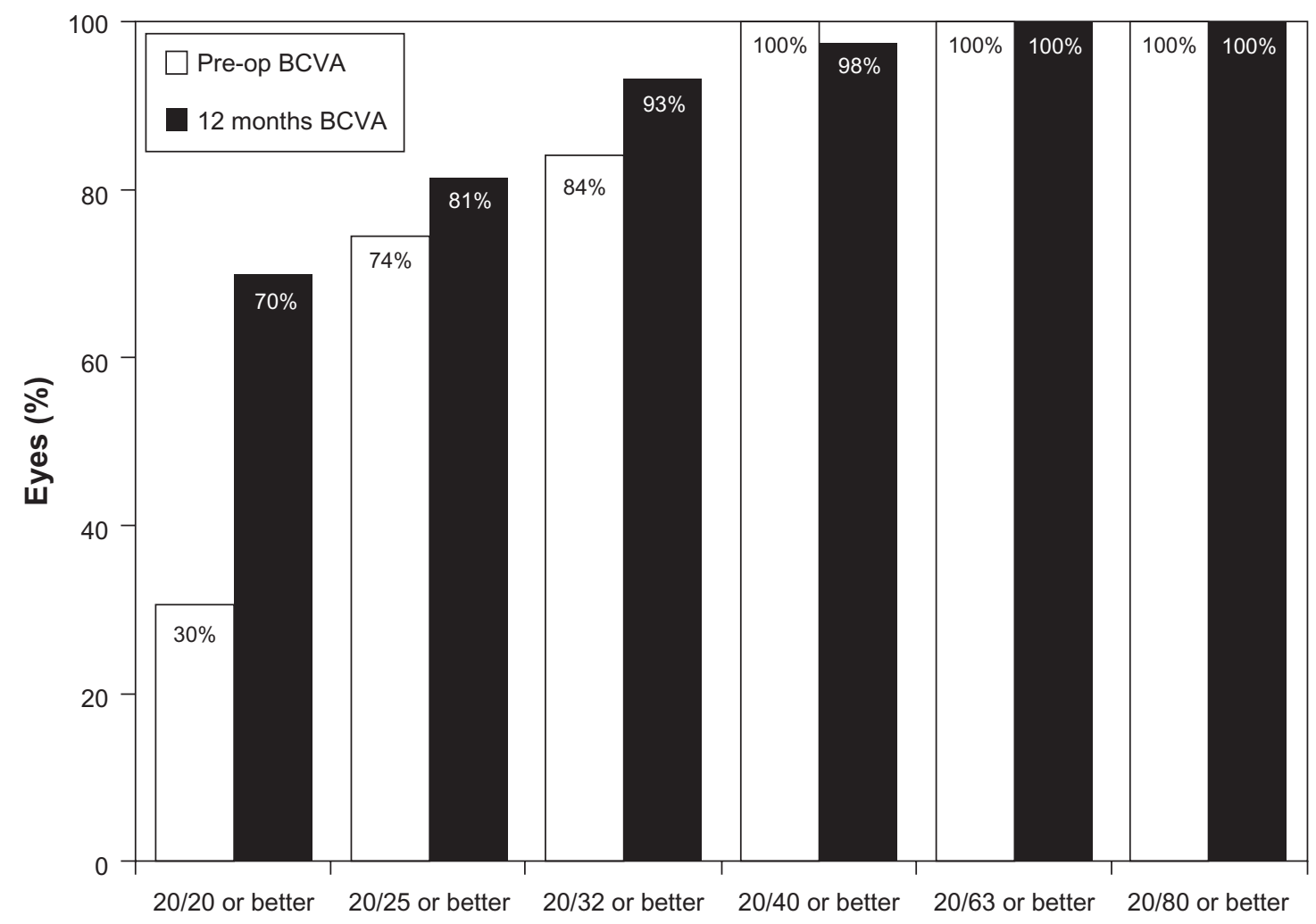

\section{Cumulative snellen visual acuity}

Figure 7 Preoperative versus I2-month postoperative best-corrected distance visual acuity (BCVA) after toric implantable collamer lens implantation. 


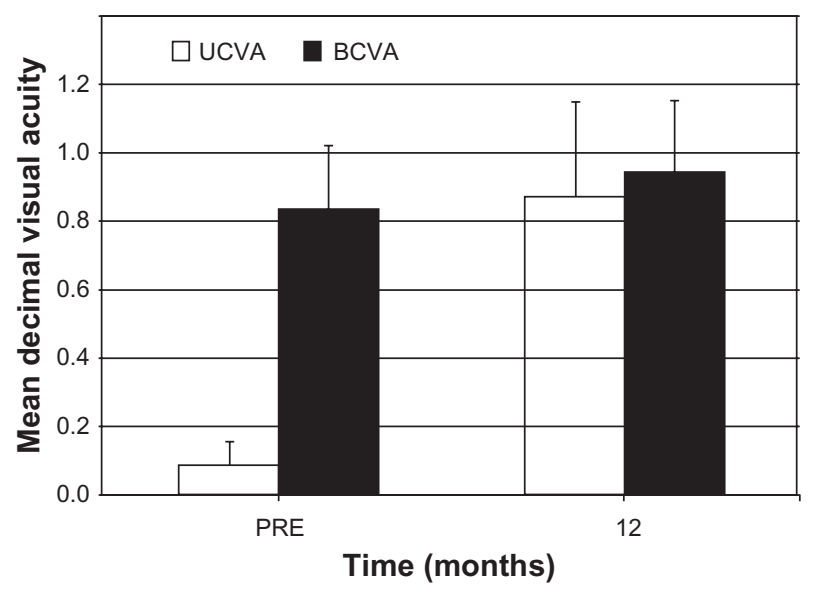

Figure 8 Uncorrected distance visual acuity (UCVA) and best-corrected distance visual acuity (BCVA) before and after toric implantable collamer lens implantation.

\section{Discussion}

The present prospective study of 43 eyes of 23 patients analyzed the correction of myopic astigmatism with toric ICL implantation. The aim of the study was to determine in our series whether this technique is a safe, predictable, and effective alternative for correcting myopia and astigmatism using pIOLs.

Our outcomes revealed that toric ICL implantation is highly predictable, stable and safe up to a period of 12 months postsurgery. The majority of eyes maintained or improved their BCVA, which resulted in a high safety index (1.14). Only one eye lost 2 lines of BCVA at 12 months. Conversely more than $60 \%$ of eyes showed a gain in BCVA (Figure 6). In addition, over $80 \%$ of eyes had BCVA of $20 / 25$ or better at 12 months and the percent of eyes with BCVA of 20/20 or better increased from $30 \%$ preoperatively to $70 \%$ after toric ICL implantation (see Figure 7 for a full description of cumulative visual acuity pre- and postsurgery).

In order to compare with previous studies reporting data of the toric ICL, the US FDA toric ICL clinical study ${ }^{8}$ showed that the toric ICL implantation is a predictable and effective method for treating moderate to high astigmatism. In that study $76.4 \%$ of patients gained $\geq 1$ line of BCVA postoperatively and $76.5 \%$ of cases had postoperative UCVA better than or equal to preoperative BCVA, with $1.6 \%$ of eyes lost $\geq 2$ lines of BCVA after 12 months. It was also reported an improvement in mean manifest $\mathrm{M}$ value from $-9.36 \mathrm{D}$ preoperatively to $0.05 \mathrm{D}$ postoperatively, with $76.9 \%$ of eyes within $\pm 0.50 \mathrm{D}$ and $97.3 \%$ within $\pm 1.00 \mathrm{D}$ as well a reduction of $73.6 \%$ in astigmatism with a mean manifest refractive cylinder reduction from $1.93 \mathrm{D}$ to $0.51 \mathrm{D}$ at 12 months. Chang and $\mathrm{Lau}^{9}$ analyzed the toric ICL on 44 Asian eyes at
6 months showing comparable outcomes to the FDA toric ICL study. ${ }^{8}$ Recently, Alfonso et $\mathrm{al}^{10}$ analyzed 55 eyes implanted with the toric ICL at 12 months and reported high correlations between attempted and achieved refractive changes for sphere and cylinder components $\left(r^{2} \geq 0.97\right)$ with $100 \%$ of eyes within $\pm 1.00 \mathrm{D}$, and more than $90 \%$ of eyes within \pm 0.50 D. A similar study of these authors ${ }^{11}$ reported the analysis of the toric ICL in highly astigmatic eyes ( $>4 \mathrm{D}$ of cylinder) showing also good outcomes with $93.3 \%$ of eyes having less than $1.00 \mathrm{D}$ of cylinder. The mean spherical equivalent was $-0.31 \pm 0.42 \mathrm{D}$ (range -1.00 to $0.75 \mathrm{D}$ ), with more than $70 \%$ of eyes within $\pm 0.50 \mathrm{D}$ of the target. For the astigmatic components, $93.3 \%$ of eyes were within $\pm 1.00 \mathrm{D}$ of $\mathrm{J}_{0}$ and all eyes were within $\pm 1.00 \mathrm{D}$ of $\mathrm{J}_{45}$. The results of our study agree with those previously reported by these authors.

In addition, it is interesting to consider that toric ICL implantation has also been used in cases where keratorefractive or alternative corrective refractive procedures were not a feasible option. For example, Kamiya et a ${ }^{19}$ reported a marked improvement in UCVA and BCVA in two patients with nonprogressive keratoconus, showing a reduction in the manifest refraction from $-10.00-6.00 \times 100^{\circ} \mathrm{D}$ and -8.00 $-2.75 \times 100^{\circ} \mathrm{D}$ to $+0.50-1.00 \times 90^{\circ} \mathrm{D}$ and -0.25 $-1.25 \times 100^{\circ} \mathrm{D}$ after surgery. Mertens et $\mathrm{al}^{20}$ reported a bilateral implantation of a custom-designed toric ICL in a patient with preoperative subjective refractive cylinder of $-5.25 \times 6^{\circ}$ in the right eye and $-5 \times 176^{\circ}$ in the left eye, changing to $-0.5 \times 77^{\circ}$ and $-0.5 \times 115^{\circ}$ after toric ICL implantation, respectively. UCVA improved to 20/20 in the right eye and 20/16 in the left eye, and BCVA improved to 20/16 in the right eye and 20/10 in the left eye. In a series of 15 eyes with spherical ICL and toric ICL implantation after penetrating keratoplasty, Alfonso et $\mathrm{al}^{21}$ reported an improvement in BCVA, with $80 \%$ of eyes having BCVA of 20/40 or better at 24 months postoperatively. About $46 \%$ of eyes gained $\geq 1$ lines of BCVA, $52 \%$ of all eyes did not change their BCVA, and no patients lost $\geq 1$ lines of BCVA at follow-up. Furthermore, $66.6 \%$ of eyes were within $\pm 0.50 \mathrm{D}$ in $\mathrm{M}$ and astigmatic components showing values nearly $100 \%$ within $\pm 1.00 \mathrm{D}$ in all eyes. Good outcomes of these previous studies should be taken into account to consider toric ICL implantation.

In relation to adverse effects, the main concern related to ICL implantation are anterior subcapsular cataract and increased IOP, ${ }^{24-28}$ presumably as a result of mechanical contact of the ICL with the anterior lens capsule, or pigment dispersion 
and pupillary block due to angle closure, respectively. In our study, no chronic increased postoperative IOP was found and no eye developed anterior subcapsular cataract over the entire follow-up period. Furthermore, mean central separation between the toric ICL and the crystalline lens (vault) during entire follow-up of this study was good and stable. Longer follow-up is needed to properly analyze long-term effects of the Toric ICL on the ocular structures.

To summarize, the results of the present study analyzing the toric ICL for myopic astigmatism correction showed that this procedure is safe, stable, and predictable during the 12 months period of follow-up. Our results agree with those reported with this lens previously.

\section{Disclosure}

The author reports no conflicts of interest in this work.

\section{References}

1. Lovisolo CF, Reinstein DZ. Phakic intraocular lenses. Surv Ophthalmol. 2005;50(6):549-587.

2. Sanders DR, Doney K, Poco M. United States Food and Drug Administration clinical trial of the Implantable Collamer Lens (ICL) for moderate to high myopia: three-year follow-up. Ophthalmology. 2004; 111(9):1683-1692.

3. Arne JL, Lesueur LC. Phakic posterior chamber lenses for high myopia: functional and anatomical outcomes. J Cataract Refract Surg. 2000; 26(3):369-374.

4. Lackner B, Pieh S, Schmidinger G, et al. Outcome after treatment of ametropia with implantable contact lenses. Ophthalmology. 2003; 110:2153-2161.

5. Bloomenstein MR, Dulaney DD, Barnet RW, Perkins SA. Posterior chamber phakic intraocular lens for moderate myopia and hyperopia. Optometry. 2002;73(7):435-446.

6. Davidorf JM, Zaldivar R, Oscherow S. Posterior chamber phakic intraocular lens for hyperopia of +4 to +11 diopters. J Refract Surg. 1998;14(3):306-311.

7. Pesando PM, Ghiringhello MP, Di Meglio G, Fanton G. Posterior chamber phakic intraocular lens (ICL) for hyperopia: ten-year follow-up. J Cataract Refract Surg. 2007;33(9):1579-1584.

8. Sanders DR, Schneider D, Martin R, et al. Toric Implantable Collamer Lens for moderate to high myopic astigmatism. Ophthalmology.

9. Chang J, Lau S. Toric Implantable Collamer Lens for high myopic astigmatic Asian eyes. Ophthalmology. 2009;116(12):2340-2347.

10. Alfonso JF, Fernandez-Vega L, Fernandes P, Gonzalez-Meijome JM, Montes-Mico R. Collagen copolymer toric posterior chamber phakic intraocular lens for myopic astigmatism: one-year follow-up. J Cataract Refract Surg. 2010;36(4):568-576. 2007;114(1):54-61.

11. Alfonso JF, Baamonde B, Madrid-Costa D, Fernandes P, Jorge J, Montes-Mico R. Collagen copolymer toric posterior chamber phakic intraocular lenses to correct high myopic astigmatism. J Cataract Refract Surg. 2010;36(8):1349-1357.

12. Elies D, Alonso T, Puig J, Gris O, Guell JL, Coret A. Visian toric implantable collamer lens for correction of compound myopic astigmatism. J Refract Surg. 2010;26(4):251-258.

13. Dick HB, Alio J, Bianchetti M, et al. Toric phakic intraocular lens: European multicenter study. Ophthalmology. 2003;110(1): $150-162$.

14. Alio JL, Mulet ME, Gutierrez R, Galal A. Artisan toric phakic intraocular lens for correction of astigmatism. J Refract Surg. 2005;21(4): 324-331.

15. Tehrani M, Dick HB. Iris-fixated toric phakic intraocular lens: Threeyear follow-up. J Cataract Refract Surg. 2006;32(8):1301-1306.

16. Alio JL, Galal A, Mulet ME. Surgical correction of high degrees of astigmatism with a phakic toric-iris claw intraocular lens. Int Ophthalmol Clin. 2003;43(3):171-181.

17. Guell JL, Morral M, Gris O, Gaytan J, Sisquella M, Manero F. Five-year follow-up of 399 phakic Artisan-Verisyse implantation for myopia, hyperopia, and/or astigmatism. Ophthalmology. 2008;115(6): 1002-1012.

18. Alio JL, Abdelrahman AM, Javaloy J, Iradier MT, Ortuno V. Anglesupported anterior chamber phakic intraocular lens explantation causes and outcome. Ophthalmology. 2006;113(12):2213-2220.

19. Kamiya K, Shimizu K, Ando W, Asato Y, Fujisawa T. Phakic toric Implantable Collamer Lens implantation for the correction of high myopic astigmatism in eyes with keratoconus. J Refract Surg. 2008; 24(8):840-842.

20. Mertens EL, Sanders DR, Vitale PN. Custom-designed toric phakic intraocular lenses to correct high corneal astigmatism. J Refract Surg. 2008;24(5):501-506.

21. Alfonso JF, Palacios A, Montes-Mico R. Myopic phakic STAAR collamer posterior chamber intraocular lenses for keratoconus. J Refract Surg. 2008;24(9):867-874.

22. Alfonso JF, Lisa C, Abdelhamid A, Montes-Mico R, Poo-López A, Ferrer-Blasco T. Posterior chamber phakic IOL after penetrating keratoplasty. J Cataract Refract Surg. 2009;35(7):1166-1173.

23. Thibos LN, Horner D. Power vector analysis of the optical outcome of refractive surgery. J Cataract Refract Surg. 2001;27(1):80-85.

24. Lackner B, Pieh S, Schmidinger G, et al. Long-term results of implantation of phakic posterior chamber intraocular lenses. J Cataract Refract Surg. 2004;30(11):2269-2276.

25. Sanders DR. Anterior subcapsular opacities and cataracts 5 years after surgery in the Visian Implantable Collamer Lens FDA trial. J Refract Surg. 2008;24(6):566-570.

26. Gonvers M, Bornet C, Othenin-Girard P. Implantable contact lens for moderate to high myopia; relationship of vaulting to cataract formation. J Cataract Refract Surg. 2003;29(5):918-924.

27. Chun YS, Park IK, Lee HI, Lee JH, Kim JC. Iris and trabecular meshwork pigment changes after posterior chamber phakic intraocular lens implantation. J Cataract Refract Surg. 2006;32(9):1452-1458.

28. Kohnen T, Kook D, Morral M, Güell JL. Phakic intraocular lenses: part 2: results and complications. J Cataract Refract Surg. 2010;36(12): 2168-2194.

\section{Dovepress}

\section{Publish your work in this journal}

Clinical Ophthalmology is an international, peer-reviewed journal covering all subspecialties within ophthalmology. Key topics include: Optometry; Visual science; Pharmacology and drug therapy in eye diseases; Basic Sciences; Primary and Secondary eye care; Patient Safety and Quality of Care Improvements. This journal is indexed on

PubMed Central and CAS, and is the official journal of The Society of Clinical Ophthalmology (SCO). The manuscript management system is completely online and includes a very quick and fair peer-review system, which is all easy to use. Visit http://www.dovepress.com/ testimonials.php to read real quotes from published authors. 